\title{
A prospective study of smoking during pregnancy and SIDS
}

Kirsten Wisborg, Ulrik Kesmodel, Tine Brink Henriksen, Sjurdur Frodi Olsen, Niels Jørgen Secher

\begin{abstract}
Aims-To study the association between smoking during pregnancy and sudden infant death syndrome (SIDS) using prospectively collected data, making it possible to account for a number of potential confounders.

Design-Prospective follow up study (n = 24 986).

Results-The overall rate of SIDS was 0.80 per 1000 live births $(n=20)$. Children of smokers had more than three times the risk of SIDS compared with children of non-smokers $(\mathrm{OR}=3.5 ; 95 \%$ CI 1.4-8.7), and the risk of SIDS increased with the number of cigarettes smoked per day ( $p<0.05)$. Adjustment for parity, alcohol, and caffeine intake during pregnancy, maternal height and weight before pregnancy, years of school, occupational status, marital status, and number of antenatal care visits did not change the results. Adjustment for mother's age marginally reduced the risk of SIDS associated with smoking $(\mathrm{OR}=3.0 ; 95 \%$ CI $1.2-$ 7.3).

Conclusions-Given the prospective nature of the study, the number of deaths is small; however, if our results reflect a true association between smoking during pregnancy and SIDS, approximately $30-40 \%$ of all cases of SIDS could be avoided if all pregnant women stopped smoking in a population with $30 \%$ pregnant smokers. Our study adds to earlier evidence for an association between smoking during pregnancy and SIDS. The strengths of the study are the possibility to adjust for a number of potential confounders and the fact that information about smoking habits during pregnancy was prospectively collected.

(Arch Dis Child 2000;83:203-206)
\end{abstract}

Keywords: smoking; pregnancy; SIDS

In industrialised countries, sudden infant death syndrome (SIDS) may account for $40 \%$ of all deaths from 1 month to 1 year of age. ${ }^{1}$ The sleeping position of the infant ${ }^{2}$ and the smoking habits of the mother ${ }^{3-9}$ have been identified as possible causal factors of SIDS. Since the beginning of the 1990s, the medical communities in Australia and several northern European countries have advocated a nonprone sleeping position of infants. This was followed by notable decreases in SIDS occur- rences, thus substantiating the infant's sleeping position as a causal factor. ${ }^{10}$

Epidemiological evidence linking SIDS with smoking derives from case control studies ${ }^{5-8} 11$ and register based studies. ${ }^{349}$ While results from case control studies are prone to recall bias as a result of differential accuracy of information from case and control parents, ${ }^{12}$ the register based studies may be biased by insufficient confounder control. ${ }^{13}$ Thus, there is still controversy about whether the apparent association between smoking and SIDS can be explained by differences in social factors or other lifestyle variables between smokers and non-smokers.

The putative effect of smoking on SIDS may be mediated through changes in the oxygen sensitivity of the peripheral arterial chemoreceptors, leading to increased vulnerability to hypoxic episodes. ${ }^{14-16}$ Furthermore, exposure to nicotine may influence the maturing of cardiorespiratory control, leading to cardiac arrhythmia. ${ }^{17}$ Finally, it has been suggested that nicotine may potentiate the lethal action of certain SIDS associated bacterial toxins. ${ }^{18}$

The aim of the present study was therefore to evaluate the association between smoking during pregnancy and SIDS, using prospectively collected data from a university ward, and making it possible to account for a number of potential confounders, including obstetric, sociodemographic, and lifestyle factors.

\section{Population and methods}

All pregnant women booking for delivery at the Department of Obstetrics and Gynaecology, Aarhus University Hospital, from September 1989 to August 1996 were invited to participate in the study. The women were asked to fill in three questionnaires: the first two before the routine antenatal visit at 16 weeks of gestation, and the third before the visit at 30 weeks of gestation.

Information from the first questionnaire was used to establish the women's medical record. It provided information on medical and obstetric history, maternal age, and smoking habits before pregnancy and during the first trimester, and alcohol intake during pregnancy. The second questionnaire provided information on marital status, education, occupational status, and caffeine intake during pregnancy. The third questionnaire was used only to register smoking habits during pregnancy. Information about delivery was obtained from a birth registration form filled in by the attending midwife immediately after delivery. Before data entry, all birth registration 
Table 1 SIDS according to smoking habits during pregnancy and other lifestyle and sociodemographic factors

\begin{tabular}{|c|c|c|c|c|}
\hline & & Total no. & $\begin{array}{l}\text { Number } \\
\text { with SIDS }\end{array}$ & $\% o$ \\
\hline \multirow[t]{3}{*}{ Cigarettes/day } & 0 & 17536 & 8 & 0.46 \\
\hline & $1-9$ & 3249 & 5 & 1.54 \\
\hline & $10+$ & 4201 & 7 & 1.67 \\
\hline \multirow[t]{2}{*}{ Parity } & Primiparous & 12750 & 10 & 0.78 \\
\hline & Multiparous & 12236 & 10 & 0.82 \\
\hline \multirow[t]{3}{*}{ Number of antenatal care visits } & $1-9$ & 9336 & 8 & 0.86 \\
\hline & $10+$ & 13401 & 11 & 0.82 \\
\hline & Missing & 2249 & 1 & 0.44 \\
\hline \multirow[t]{2}{*}{ Sex of the child } & Male & 12834 & 10 & 0.78 \\
\hline & Female & 12152 & 10 & 0.82 \\
\hline \multirow{2}{*}{ Maternal age (y) } & $15-24$ & 4633 & 10 & 2.16 \\
\hline & $25-50$ & 20353 & 10 & 0.49 \\
\hline \multirow[t]{3}{*}{ Marital status } & Cohabiting & 20176 & 14 & 0.69 \\
\hline & Single & 916 & 2 & 2.18 \\
\hline & Missing & 3894 & 4 & 1.03 \\
\hline \multirow[t]{3}{*}{ Years of education } & $<10$ & 7526 & 8 & 1.06 \\
\hline & $10+$ & 10502 & 5 & 0.48 \\
\hline & Missing & 6958 & 7 & 1.01 \\
\hline \multirow[t]{4}{*}{ Occupational status during pregnancy } & Working & 11961 & 10 & 0.84 \\
\hline & Unemployed & 3853 & 2 & 0.52 \\
\hline & Student & 1895 & 1 & 0.53 \\
\hline & Missing & 7277 & 7 & 0.96 \\
\hline \multirow{3}{*}{$\begin{array}{l}\text { Caffeine intake during pregnancy } \\
(\mathrm{mg} / \text { day })\end{array}$} & $<400$ & 12107 & 8 & 0.66 \\
\hline & $400+$ & 6407 & 6 & 0.94 \\
\hline & Missing & 6472 & 6 & 0.93 \\
\hline \multirow{4}{*}{$\begin{array}{l}\text { Alcohol intake during pregnancy } \\
\text { (drinks/week) }\end{array}$} & 0 & 16539 & 15 & 0.91 \\
\hline & $1-2$ & 5581 & 2 & 0.36 \\
\hline & $3+$ & 2298 & 2 & 0.87 \\
\hline & Missing & 568 & 1 & 1.76 \\
\hline \multirow[t]{4}{*}{ Mother's height (cm) } & $<166$ & 8447 & 6 & 0.71 \\
\hline & $166-170$ & 8149 & 5 & 0.61 \\
\hline & $171+$ & 7955 & 8 & 1.01 \\
\hline & Missing & 435 & 1 & 2.30 \\
\hline \multirow[t]{5}{*}{ Mother's prepregnancy weight (kg) } & $<50$ & 1153 & 2 & 1.73 \\
\hline & $50-59$ & 9443 & 8 & 0.85 \\
\hline & $60-69$ & 9104 & 6 & 0.66 \\
\hline & $70+$ & 4792 & 3 & 0.63 \\
\hline & Missing & 494 & 1 & 2.02 \\
\hline
\end{tabular}

forms were manually checked and compared with the medical records by a research midwife who also registered all complications during the first days after delivery.

Information about deaths during the first year of life was obtained from the Registry of Causes of Death, administered by the Danish National Board of Health, and from the Danish Civil Registration System, administered by the Danish government. Furthermore, we reviewed the hospital records of all cases of death before one year of life to validate the cause of death. The International Classification of Diseases, 8th Revision (ICD-8) was used in Denmark to classify causes of death through 1993, and from January 1994 the 10th Revision (ICD-10) was used. SIDS was defined as death ICD-8 code 795.80 and ICD-10 code R95.9. The medical records of the children with SIDS were manually checked to ensure that the diagnosis was correct

The study population was restricted to Danish speaking women who completed the first questionnaire and carried their pregnancy to a live birth of a single child $(n=24986)$. This number corresponds approximately to $90 \%$ of all Danish speaking women booking for delivery during the study period. The second questionnaire was completed by 18517 (74\%) women, and the third by 16436 (66\%). Information about birth weight and gestational age at delivery was missing in 87 and four cases, respectively.
The women were defined as smokers if they smoked one or more cigarettes per day when 16 or 30 weeks pregnant. Only minimal changes in smoking habits appear after 16 weeks of gestation. ${ }^{19}$ Smoking was analysed in two categories (smokers versus non-smokers), and also in ordered categories: $0,1-9$, and 10 or more cigarettes per day.

\section{STATISTICAL ANALYSIS}

The association between smoking during pregnancy and SIDS is presented as odds ratios (OR) with $95 \%$ confidence intervals (CI). Potential confounding variables were categorised as in table 1 . They were evaluated in logistic regression analyses, and if they changed the measure of association between smoking and SIDS by more than $10 \%$ they remained in the final model.$^{20}$ All covariates were entered as ordinal, creating a number of dummy variables equal to the number of categories minus one. To take into account the time of death after delivery, all measures of association were evaluated in a Cox regression analysis. However, as the results were similar to those from logistic regression analyses, they are not presented. Differences in mean birth weight were evaluated by analysis of variance. The attributable fraction (AF) was calculated from the following formula ${ }^{21}$ :

$\mathrm{AF}=\frac{\text { proportion of exposed in the population } \times(\mathrm{OR}-1)}{\text { proportion of exposed in the population } \times(\mathrm{OR}-1)+1}$

The study was approved by the regional ethics committee and by the Danish National Board of Health.

\section{Results}

The study group consisted of 24986 live born children. In $7450(30 \%)$ pregnancies the mother was categorised as a smoker and in $17536(70 \%)$ pregnancies as a non-smoker. Among those categorised as non-smokers, $2642(15 \%)$ had smoked before pregnancy but stopped during the first trimester. Among smokers, 3249 (44\%) smoked 1-9 cigarettes per day, and 4201 (56\%) 10 or more cigarettes per day. The mean number of cigarettes smoked per day was 9 (5).

The overall rate of SIDS was 0.80 per 1000 live births $(n=20)$. The median age at death among children who died from SIDS was 69 days $(25 \%$ percentile 40 days; $75 \%$ percentile 109 days). The mean age at death was 27 days ( $95 \%$ CI -15 to 69 days) less among children born to women who had smoked during pregnancy compared with children of non-smokers.

The crude analysis showed that children of smokers had more than three times the risk of SIDS than children of non-smokers (table 2). The risk of SIDS increased with the number of cigarettes smoked per day (test for trend $\mathrm{p}<0.05$; table 2). Adjustment for parity, alcohol, and caffeine intake during pregnancy, maternal height and weight before pregnancy, years of school, occupational status, marital status, and number of antenatal care visits did not change the results. Adjustment for mother's age reduced the risk of SIDS associated 
Table 2 Crude and adjusted OR of SIDS according to different categories of smoking habits during pregnancy

\begin{tabular}{lcrll}
\hline & Total no. & $\begin{array}{c}\text { No. with } \\
\text { SIDS }\end{array}$ & $\%$ \%o & $\begin{array}{l}\text { Adjusted* } \\
\text { OR }(95 \% \text { CI) }\end{array}$ \\
\hline Non-smokers from 16 weeks gestation & 17536 & 8 & 0.5 & Reference \\
Smokers & 7450 & 12 & 1.6 & $3.5(1.4-8.7)$ \\
1-9 cigarettes/day & 3249 & 5 & 1.5 & $3.4(1.1-10.3)$ \\
10+ cigarettes/day & 4201 & 7 & 1.7 & $3.7(1.3-10.1)$ \\
\hline
\end{tabular}

^Adjusted for maternal age.

with smoking (table 2). Mean birth weight was $323 \mathrm{~g} \mathrm{(95 \%} \mathrm{CI} 81$ to $566 \mathrm{~g})$ lower among children who died from SIDS than among surviving children. Adjustment for birth weight and gestational age at birth also reduced the risk of SIDS associated with smoking $(\mathrm{OR}=2.9$; $95 \%$ CI 1.2 to 7.2 ). Conclusions were not changed after adjustment for maternal age, birth weight, and gestational age at birth.

\section{Discussion}

In this prospective study of smoking during pregnancy and SIDS, children of women who smoked during pregnancy had an increased risk of SIDS compared with children born to women who had not smoked during pregnancy. Despite a small numbrer of cases and controlling for possible confounders the association was statistically significant. The risk of SIDS increased with the number of cigarettes smoked per day during pregnancy.

Information about smoking habits during pregnancy was obtained from a self administered questionnaire completed by the pregnant women at 16 and 30 weeks of gestation. Because the data were collected prospectively, information about smoking could not be biased by the parents' knowledge about the death of their child. With only 20 cases, it was not meaningful to assess any differential effect between smoking at weeks 16 and 30 . Furthermore, among 8607 women (34\%) information was missing about smoking habits at 30 weeks of gestation. In our population $30-40 \%$ of the smokers stopped smoking in early pregnancy, but after the first trimester very few stopped smoking. ${ }^{23}$ Thus, smoking habits at 16 weeks of gestation are a valid measure of smoking habits throughout pregnancy.

Women who stopped smoking before 16 weeks of gestation were categorised as nonsmokers in the present study. However, if exposure in early pregnancy is associated with an increased risk of SIDS, compared with no exposure during the entire pregnancy, our result is an underestimation of the true association between smoking during pregnancy and SIDS.

Owing to careful prospective collection of information about maternal lifestyle, and sociodemographic and obstetric factors, we could adjust for a variety of potential confounders. Adjustment for maternal age marginally decreased the risk of SIDS associated with smoking. However, maternal age may represent a proxy for other factors associated with smoking and the occurrence of SIDS, for example, attitudes towards childcare. It is possible that controlling for those factors would further decrease the risk of SIDS associated with smoking. Furthermore, information about socioeconomic markers was missing in one third of all women which may constrain the possibility to fully adjust for these factors.

We did not have information on smoking by the mothers after delivery. However, this is likely to be closely associated with smoking habits during pregnancy. For outcomes assessed shortly after birth, any attempt to discriminate between effects of maternal smoking during pregnancy or after birth remains speculative. It is therefore possible that the association identified in this study may be caused by smoking exposure after delivery.

Unlike Schellscheidt and coworkers ${ }^{24}$ we found that SIDS children had a lower mean birth weight than with surviving infants. Some children might be more vulnerable to tobacco exposure in utero, but it is also possible that women whose children died from SIDS smoked more than they actually reported, or smoked differently from mothers with surviving infants. Biochemical measures of tobacco exposure could throw light on this problem. The risk of SIDS was marginally reduced after adjustment for birth weight. Thus our result may indicate that smoking increases the risk of SIDS in addition to its effect on birth weight and preterm delivery.

Our study adds to earlier evidence for an association between smoking during pregnancy and SIDS. The study's strengths are the possibility to adjust for a number of potential confounders and the fact that information about smoking habits during pregnancy was prospectively collected. Given the prospective nature of the study, the number of deaths is small: however, if the association between maternal smoking and SIDS found in this and previous studies reflects a causal relation, approximately $30-40 \%$ of all cases of SIDS could be avoided if all pregnant women stopped smoking in a population with $30 \%$ pregnant smokers.

1 Willinger M. SIDS prevention. Pediatr Ann 1995;24:35864

2 Oyen N, Markestad T, Skaerven R, et al. Combined effects of sleeping position and prenatal risk factors in sudden infant death syndrome: the Nordic Epidemiological SIDS Study. Pediatrics 1997;100:613-21.

3 Haglund B, Cnattingius S. Cigarette smoking as a risk factor for sudden infant death syndrome: a population-based study. Am F Public Health 1990;80:29-32.

4 Malloy MH, Kleinman JC, Land GH, Schramm WF. The association of maternal smoking with age and cause of infant death. Am f Epidemiol 1988;128:46-55.

5 Schoendorf KC, Kiely JL. Relationship of sudden infant death syndrome to maternal smoking during and after pregnancy. Pediatrics 1992;90:905-8.

6 Malloy MH, Hoffman HJ, Peterson DR. Sudden infant death syndrome and maternal smoking. Am $\mathcal{f}$ Public Health 1992;82:1380-2.

7 Ponsonby AL, Dwyer T, Kasl SV, Cochrane JA. The Tasmanian SIDS Case-Control Study: univariable and multivariable risk factor analysis. Paediatr Perinat Epidemiol 1995;9: $256-72$.

8 Blair PS, Fleming PJ, Bensley D, et al. Smoking and the sudden infant death syndrome: results from 1993-5 case-control study for confidential inquiry into stillbirths and deaths in infancy. Confidential Enquiry into Stillbirths and Deaths Regional Coordinators and Researchers. BMf 1996;313:195-8.

9 Lewak N, van den Berg BJ, Beckwith JB. Sudden infant death syndrome risk factors. Prospective data review. Clin Pediatr (Phila) 1979;18:404-11.

10 Hiley CM, Morley CJ. Evaluation of government's campaign to reduce risk of cot death. BMF 1994;309:703-4

11 Mitchell EA, Ford RP, Stewart AW, et al. Smoking and the sudden infant death syndrome. Pediatrics 1993;91:893-6. 
12 Gibbons LE, Ponsonby AL, Dwyer T. A comparison of prospective and retrospective responses on sudden infan death syndrome by case and control mothers. Am f Epidemiol 1993;137:654-9.

13 Marshall JR, Hastrup JL. Mismeasurement and the resonance of strong confounders: uncorrelated errors. $A m \mathcal{F}$ Epidemiol 1996;143:1069-78.

14 Holgert H, Hokfelt T, Hertzberg $T$, Lagercrantz $H$. Functional and developmental studies of the peripheral arterial chemoreceptors in rat: effects of nicotine and possible relation to sudden infant death syndrome. Proc Nat Acad Sci U S A 1995;92:7575-9.

15 Lewis KW, Bosque EM. Deficient hypoxia awakening response in infants of smoking mothers: possible relationship to sudden infant death syndrome. F Pediatr 1995;127: 691-9.

16 Krous HF, Campbell GA, Fowler MW, Catron AC, Farber JP. Maternal nicotine administration and fetal brain stem damage: a rat model with implications for sudden infant death syndrome. Am 7 Obstet Gynecol 1981;140:743-6.

17 Meny RG, Carroll JL, Carbone MT, Kelly DH. Cardiorespiratory recordings from infants dying suddenly and unexpectedly at home. Pediatrics 1994;93:44-9.
18 Sayers NM, Drucker DB, Telford DR, Morris JA. Effects of nicotine on bacterial toxins associated with cot death. Arch nicotine on bacterial toxin
Dis Child 1995;73:549-51.

19 Wisborg K, Henriksen TB, Hedegaard M, Secher NJ. Rygevaner blandt gravide samt sociodemografiske faktorers betydning for rygeophør [Smoking cessation among pregnant women]. Ugeskr Laeger 1996;158:3784-8.

20 Greenland S. Modeling and variable selection in epidemiologic analysis. Am F Public Health 1989;79:340-9.

21 Walter SD. Calculation of attributable risks from epidemiological data. Int f Epidemiol 1978;7:175-82.

22 Wisborg K, Henriksen TB, Hedegaard M, Secher NJ. Smoking habits among Danish pregnant women from 1989 to 1996 in relation to sociodemographic and lifestyle factors. Acta Obstet Gynecol Scand 1998;77:836-40.

23 Wisborg K, Henriksen TB, Secher NJ. A prospective intervention study of stopping smoking in pregnancy in a routine antenatal care setting. Br $\quad \mathfrak{f}$ Obstet Gynaecol 1998;105:1171-6.

24 Schellscheidt J, Jorch G, Menke J. Effects of heavy maternal smoking on intrauterine growth patterns in sudden infant smoking on intrauterine growth patterns in sudden infant
death victims and surviving infants. Eur f Pediatr 1998;157: $246-51$.

\section{Call for Papers}

\section{6th European Forum on Quality Improvement in Health Care}

\section{Thursday 29-Saturday 31 March 2001, Bologna, Italy}

For full information contact: BMA/BMJ Conference Unit, BMA House, Tavistock Square, London WC1H 9JP, UK. Tel: +44 (0) 207383 6409; fax: +44 (0) 207383 6869; email: quality@bma.org.uk; website: www.quality.bmjpg.com 


\section{LETTERS TO THE EDITOR}

\section{Rapid responses}

If you have a burning desire to respond to a paper published in $A D C$ or $F \mathcal{E} N$, why not make use of our "rapid response" option?

Log on to our website (www. archdischild.com), find the paper that interests you, click on "full text" and send your response by email by clicking on "submit a response".

Providing it isn't libellous or obscene, it will be posted within seven days. You can retrieve it by clicking on "read rapid responses" on our homepage.

The editors will decide, as before, whether to also publish it in a future paper issue.

Protective role of cerebrospinal fluid in brain injuries

EdiToR,-We would like to offer a simple model of brain injury which explains many features of "closed skull" injuries-that is, those where damage results from the action of inertial forces only.

The model is easily constructed as follows. Fill a jam jar to the brim with water. Glue two threads to an egg, suspend the egg in the water, and screw the lid on tightly. If the jar is shaken horizontally as vigorously as possible, the egg will not usually touch the sides of the jar, let alone break. If, however, the jar is suddenly and impulsively rotated, one of the threads will normally break or pull away a small portion of the shell at the point of attachment.

Standard fluid mechanics explains why the egg is not damaged by linear motion. ${ }^{1}$ The acceleration of the jar gives rise to three fluid forces opposing the motion of the egg: a force due to the horizontal pressure gradient, the "acceleration reaction", and the viscous drag. Together, these three forces can be shown to reduce the acceleration of the egg relative to the jar by a factor of 40-50, compared with what it would have been in the absence of the water. When the jar is rotated, inertia tends to keep the egg fixed in space and, as the water is incapable of exerting any significant moment on the egg, the thread breaks.

If we identify the egg with the brain, the water with the cerebrospinal fluid, the jar with the skull, and a broken thread with a bleeding bridging vein, we have a ready explanation for the generally accepted fact that brain injury is more easily caused by rotational than by linear acceleration. ${ }^{2}$

As the argument is based on known fluid mechanical principles, the important question is the extent to which the model represents a real head. The model ignores the presence of the brain stem. However, this approximation is justified, at least for small movements, because the neurovascular structures in the brain stem permit small linear and rotational movements of the brain before any significant forces come into play. Apart from the published animal studies, verification of this model would require experiments with an instrumented cadaver head or an advance in imaging technology to permit real time tracking of the brain's movement.

D C HODGSON J M SHIPPEN School of Manufacturing and Mechanical Engineering, University of Birmingham, Birmingham B15 2TT, UK

R SUNDERLAND Consultant Paediatrician, Birmingham Children's Hospital, Birmingham B4 6NH, UK

1 Batchelor GK. Fluid dynamics. Cambridge: Cambridge University Press, 1967.

2 Gennarelli TA, Thibault LE. Biomechanics of acute subdural haematoma. F Trauma 1982;22: acute subd

\section{Oral steroids and inflammatory} markers in asthma

EDITOR,-Although the recent paper by El-Radhi and colleagues presents interesting data about decreases in inflammatory markers during the resolution of acute asthma, ${ }^{1}$ some of their conclusions are not valid. Firstly, acute asthma has a tendency to resolve without corticosteroid treatment. ${ }^{2}$ As all of the children with acute asthma (quite rightly) received steroids, the observed effect may equally reflect processes associated with spontaneous resolution. Indeed, corticosteroids do not inhibit the release of eosinophil cationic protein (ECP) from eosinophils. ${ }^{3}$ Secondly, the normal controls are inadequate. Atopy per se is associated with increased serum levels of $\mathrm{ECP},{ }^{4}$ and it is therefore to be expected that the asymptomatic atopic asthmatics will have higher ECP levels than the mostly non-atopic controls.

J GRIGG

Dept of Child Health, Clinical Sciences Building, Leicester Royal Infirmary, PO Box 65, Leicester LE2 7LX, UK

1 El-Radhi AS, Hogg CL, Bungre JK, et al. Effect of oral glucocorticoid treatment on serum inflammatory markers in acute asthma. Arch Dis Child 2000;83:158-62.

2 Gleeson JG, Loftus BG, Price JF. Placebo controlled trial of systemic corticosteroids in acute childhood asthma. Acta Paediatr Scand 1990;79:1052-8.

3 Venge P, Bystrom J, Carlson M, et al. Eosinophil cationic protein (ECP): molecular and biological properties and the use of ECP as a marke of eosinophil activation in disease. Clin Exp 29:1172-86.

4 Remes S, Korppi M, Remes K, et al. Serum eosinophil cationic protein (ECP) and eosinophil protein X (EPX) in childhood asthma: the influence at atopy. Pediatr Pulmonol 1998;26: $167-74$

Table 2 Crude and adjusted OR of SIDS according to different categories of smoking habits during pregnancy

\begin{tabular}{lcccll}
\hline & Total no. & $\begin{array}{c}\text { Total no. } \\
\text { with SIDS }\end{array}$ & $\%$ OR (95\% CI) & $\begin{array}{l}\text { Adjusted } \text { OR }^{\star} \\
(95 \% \text { CI) }\end{array}$ \\
\hline Non-smokers from 16 weeks' gestation & 17536 & 8 & 0.5 & Reference & Reference \\
Smokers & 7450 & 12 & 1.6 & $3.5(1.4-8.7)$ & $3.0(1.2-7.3)$ \\
1-9 cigarettes/day & 3249 & 5 & 1.5 & $3.4(1.1-10.3)$ & $2.9(0.9-8.9)$ \\
10+ cigarettes/day & 4201 & 7 & 1.7 & $3.7(1.3-10.1)$ & $3.0(1.1-8.5)$
\end{tabular}

^Adjusted for maternal age
Reliability of percentage ideal weight

EDITOR,-I write to point out an error in a recent paper by Poustie and colleagues. ${ }^{1}$ The authors state that there is no computer package available in the United Kingdom for calculating percentage weight for height (\%WFH). This is incorrect, and for many years there has been available just such a package entitled $\mathrm{W} 4 \mathrm{H}$, under the copyright of Great Ormond Street Hospital for Children NHS Trust. The programme can be used with any version of Windows from 3.1 upwards, Excel, and on Psion hand held computers. The programme was produced by the Eating Disorders Research Team at Great Ormond Street and can be purchased from me at the address given below. ( St George's Hospital Medical School, London SW17 ORE, UK blask@swlstg-tr.nhs.uk

1 Poustie VJ, Watling RM, Ashby D, et al. Reliability of percentage ideal weight for height. Arch Dis Child 2000;83:183-4.

Answers to quiz on page 164.

1. Adult respiratory distress syndrome and sand aspiration. The spirometry findings suggest air trapping by grains of sand, causing blockage of inspiration and expiration via a ball valve mechanism.

2. A CT scan of the lungs and a bronchoscopy, with diagnostic and therapeutic lavage.

3. Drowning and near drowning account for a significant morbidity and mortality in children, especially in seawater areas. The incidence of aspiration of mud, sand, and aquatic vegetation is less well known. A high index of suspicion is required as management may include diagnostic and therapeutic endobronchial/alveolar lavage. Initial clues to significant aspiration include increased peak airway pressures during mechanical ventilation and the appearance of a sand bronchogram on the $x$ ray.

\section{CORRECTION}

An error occurred in table 2 of Wisborg and colleagues' recent paper (Arch Dis Child 2000;83:203-6). The correct figures are given in the table printed below: for height 